

Thomas de Graaff

Henri L.F. de Groot*

Faculty of Economics and Business Administration, Vrije Universiteit Amsterdam,

* Tinbergen Institute. 


\section{Tinbergen Institute}

The Tinbergen Institute is the institute for economic research of the Erasmus Universiteit Rotterdam, Universiteit van Amsterdam, and Vrije Universiteit Amsterdam.

Tinbergen Institute Amsterdam

Roetersstraat 31

1018 WB Amsterdam

The Netherlands

Tel.: $\quad+31(0) 205513500$

Fax: $\quad+31(0) 205513555$

Tinbergen Institute Rotterdam

Burg. Oudlaan 50

3062 PA Rotterdam

The Netherlands

Tel.: $\quad+31(0) 104088900$

Fax: $\quad+31(0) 104089031$

Please send questions and/or remarks of nonscientific nature to driessen@tinbergen.nl.

Most TI discussion papers can be downloaded at http://www.tinbergen.nl. 


\title{
Ethnic Concentration and Human Capital Formation*
}

\author{
Thomas de Graaff ${ }^{\dagger} \quad$ Henri L.F. de Groot ${ }^{\ddagger}$
}

July 13, 2004

${ }^{*}$ This paper is a modified version of a chapter in the Ph.D. thesis of Thomas de Graaff. The authors would like to thank Peter Nijkamp, Jos van Ommeren, Jan van Ours, Joop Hartog and an anonymous referee for useful comments. We are much indebted to Cees Gorter $^{\dagger}$, who contributed greatly to this paper and was an important source of inspiration.

${ }^{\dagger}$ Corresponding author. Free University Amsterdam, Department of Spatial Economics, De Boelelaan 1105, 1081 HV, Amsterdam, The Netherlands. Email: tgraaff@feweb.vu.nl

${ }^{\ddagger}$ Free University Amsterdam, Department of Spatial Economics, and Tinbergen Institute, De Boelelaan 1105, 1081 HV, Amsterdam, The Netherlands. Email: hgroot@feweb.vu.nl 


\begin{abstract}
Concentration of immigrants and its associated externalities have become an important topic in contemporary international migration research, both from a methodological as well as an empirical perspective. The purpose of this paper is twofold. First, it aims to provide an overview of that part of the migration literature that is concerned with the externalities created by the influx of immigrants. Second, it presents a stylized model in which human capital accumulation and ethnic cluster formation are explicitly incorporated. The model shows that lock-in effects can result from heterogeneous human capital and spillover effects on different spatial levels. Extensions of the model are discussed, together with their possible impacts on the spatial variation of the evolution of human capital stocks.
\end{abstract}

Keywords: Ethnic concentration, human capital, migration, migration costs.

JEL-code: J61, R11 


\section{Introduction}

During the last decade, an increasing body of the empirical migration literature has dealt with the phenomenon of ethnic concentration, its causes and its economic consequences (Bartel 1989, LaLonde and Topel 1991, De Graaff 2002). Traditional neoclassical migration models have been argued not to be very appropriate in explaining this stylized fact. They predict that workers migrate to those locations where their labor skills are scarce (see inter alia Greenwood and McDowell 1986, Massey et al. 1993, Borjas 1994, for comprehensive overviews of the literature). Thus, one would expect that immigrants spread out over space and sectors. Empirical evidence clearly shows the opposite: immigrants are concentrated in specific cities, neighborhoods and sectors (see De Graaff 2002, for a recent overview). Recently, economic models have been developed that are able to deal with the spatial concentration of foreign immigrants. A common characteristic of these theoretical models is the presence of externalities, which are created by migrant groups and that directly or indirectly affect the migration costs and human capital accumulation. The literature contains at least five approaches to model ethnic concentration. The most influential is that of Borjas $(1992,1995)$ who introduced the concept of ethnic capital, being a local, ethnic-specific spillover in human capital accumulation. In his view, immigrants cluster because of opportunities created by specific ethnic niches. According to Borjas, it is difficult to overestimate the importance of ethnic capital, or - in his own words -

"Ethnicity has an impact above and beyond both parental and neighborhood effects for persons who are frequently exposed to a particular ethnic environment." (Borjas 1995, p. 389)

The advantage of his theory is that it can explain different degrees of clustering among ethnic groups. The second line of research is that of Stark (1991, 1994) in which low-skilled migrants are inclined to mix with highskilled migrants in order to obscure their skill signals. Low-skilled migrants then take advantage of the imperfect information that (indigenous) employers have. Eventually, this will lead to lower wage offers to all immigrants caused by asymmetric information and thus depresses incentives to invest in human capital. Hendricks (2001) provides a third reason for migrants to cluster. He argues that due to skill complementarity and imperfectly observable worker's skills, immigrants cluster. New immigrants choose to live near existing immigrants to take advantage of cross-matching. Employers then use ethnicity as a proxy for skills. This has two strong implications: (i) incentives for clustering vary between different ethnic groups and (ii) second-generation immigrants have less incentives to cluster than first-generation immigrants because usually the former group is higher skilled than the latter. Epstein and Hillman (1998) use another argument 
based on herd behavior to explain ethnic concentration. When a large group of previous migrants has gone to location $A$, new migrants will also be attracted to $A$, even though they have information that $B$ would be the better choice. In this line of thinking, migrants take the decision of others into account, because other migrants may have access to information that they do not have. The fifth approach is that of Carrington et al. (1996), who introduce endogenous migration costs to explain ethnic clustering. The larger the stock of migrants in $A$, the lower are the migration costs for new migrants to go to $A$. Except for the approach of Borjas - who argues that ethnicity directly influences human capital accumulation - the other approaches acknowledge that some kind of network or information externalities are the cause for ethnic clustering, which in turn affects human capital accumulation.

Before focusing on the development of human capital of ethnic groups, it is insightful to look at the empirical evidence considering the relation between ethnic concentration and human capital formation. First, estimating the effect of ethnic concentration on economic outcomes is not straightforward. Ethnic composition is arguably an endogenous variable; migrants are selective in choosing for specific neighborhoods. Residential location of a migrant is therefore probably correlated with labor market outcomes due to unobserved attributes of the migrant. ${ }^{1}$ There are some ways out to circumvent this endogeneity effect in the estimation procedure. Borjas (1992, 1995) uses parental choices of residential location for the exogeneity of the economic outcomes of their offspring. Cutler and Glaeser (1997), Bertrand et al. (2000) and Dustmann and Preston (2001) avoid the endogeneity problem by using fixed spatial effects (on a city level). These studies typically show that segregation in low-skilled areas is disadvantageous for ethnic minorities. ${ }^{2}$ More recently, Edin et al. (2003) use a natural experiment to properly identify the concentration effect. They look at the economic performance of refugee immigrants who have been sorted by government authorities. Their results modify the previously described results. Living in an ethnically concentrated area improves the economic performance of immigrants ceteris paribus. However, the overall performance of the ethnic group is crucial. Immigrants who are clustered in a high-income area seem to benefit more than immigrants who are clustered in a low-income area.

To conclude, immigration tends to be associated with ethnic concentration and affects average levels of human capital within those clustered areas. This may have important consequences for human capital accumulation of not only the immigrants, but also for the indigenous population living close to the immigrant population. Since the seminal work of Lucas

\footnotetext{
${ }^{1}$ See Manski (1993) for fundamental critique on estimating social effects without proper identification.

${ }^{2}$ Ethnic minorities are commonly defined as first and second generation immigrants.
} 
(1988), the notion that dispersion and creation of knowledge take largely place within the boundaries of the city or the neighborhood has become widespread and has been further developed by authors like Durlauf (1994), Borjas (1995) and Bénabou (1996a,b). The importance of human capital can be deduced from the fact that it is the main determinant of present income (Becker 1975), and that it acts as the engine for future income growth (Romer 1986, Lucas 1988). So the externalities associated with immigration and its corresponding impacts on human capital accumulation are most likely the cause for lock-in effects of certain ethnics groups, ${ }^{3}$ their inferior economic performance in most cases, ${ }^{4}$ and their successful behavior in only few cases. ${ }^{5}$ Therefore, the contribution of this paper is twofold. First, we aim to give an overview of that part of the recent migration literature that deals with ethnic clustering and its consequences. Second, we present a basic model merging two main theories, namely, that of endogenous migration and that of human capital formation, which offers insight into the cause and dynamics of heterogeneity in human capital on the level of cities and neighborhoods.

The remainder of this paper is organized as follows. Section 2 presents the basic model, which consists of a simple economy and a decision framework for potential migrants along the lines of Sjaastad (1962). This model mainly focuses on endogenous migration between two countries and defines individual human capital accumulation. Subsequently, Section 3 presents the analytical results in a framework with homogeneous human capital both in the source country and in the country of destination. In Section 4, we relax the assumption of homogeneity. First, we focus on the dynamics of human capital accumulation when migration is skill independent. Thereafter, we assume that migration costs depend both on skills and migrant networks and look at migration dynamics and human capital accumulation in a simulation framework. The last section concludes.

\section{A Model of Migration and Human Capital Accumu- lation}

In this section, we propose a model in which we have two countries (source and destination) and where human capital and an exogenously given physical capital stock are the only production factors. Total production depends

\footnotetext{
${ }^{3}$ The Afro-American population group in the United States is a good example of an ethnic group that is characterized by lock-in effects, especially within certain neighborhoods in the larger cities.

${ }^{4}$ Most ethnic groups originating from the so-called guestworkers in the 1970s and 1980s in Western Europe perform economically consistently worse compared to the indigenous population. Later generations do not seem to be able to catch up quickly.

${ }^{5}$ Nowadays, successful migrant groups are usually formed by high-skilled immigrants (expats), with short migration spells.
} 
on total human capital, where human capital exhibits decreasing returns to scale. Individual wages are proportional to the individual's human capital. With equal human capital, there is an initial wage difference between the source and the destination country, due to country-specific technology. ${ }^{6}$ Migration between the two economies is possible, but at a cost, which depends on the stock of migrants already in the destination country and on the amount of human capital that potential migrants possess. Here, we adopt the theory of Carrington et al. (1996) of endogenous migration costs. It states that costs of migration decrease in the size of the migrant network in the country of destination, where costs are not only monetary, but also involve psychological and information (search) costs. For example, the larger a migrant network, the easier it will be for a new migrant to find a job through the job referral system as suggested by Montgomery (1991). Munshi (2003) offers an empirical study of such a job referral system used by Mexican migrants in the United States and shows that an ethnic network for new migrants is indeed beneficial, at least in the short run.

Human capital develops endogenously over time. We assume that human capital accumulation depends on three factors (Bénabou (cf. 1996b)). First, an individual's personal amount of human capital influences the process of accumulation. This reflects the influence of initial human capital endowment and transmission within the family. Second, the aggregate human capital in the individual's direct environment, i.e. the neighborhood, affects human capital formation. Apart from directly learning from neighbors, a person's direct environment plays a pivotal role in providing information, opportunities and role models. The third factor that plays a role in human capital accumulation is the aggregate amount of human capital in a country. This can be seen as reflecting the influence of average national human capital on the development of the individual's human capital, i.e. by the national education system. The influence of aggregate human capital within a spatial area is defined by constant elasticity to scale aggregator functions, where aggregate human capital is determined by a human capital spillover parameter. If the spillover parameter is positive, then variety in human capital will lead to lower aggregate human capital. If it is negative, then it will lead to higher aggregate human capital. In the former case, human capital spillovers are hampered by lack of 'transactions' (Lazear 1999). Basically, this means that there is insufficient communication due to a lack of trust, understanding or common language. The last two arguments build on the notion that when variety in human capital is too large, knowledge transfers are no longer possible. With a negative

\footnotetext{
${ }^{6}$ In this framework, country-specific technology can also be interpreted as restrictions or barriers for production, such as climate, infertile land, and geographical features (such as rivers, coastal waters and mountains). For historical examples of the effects of such restrictions on economic performance, see De Vries and Van der Wouden (1995) and Mokyr (1999). For empirical estimates of country-specific technologies, see Islam (1995).
} 
spillover parameter, there are returns to variety. In this case, individuals have a common basis (e.g., the same language) on which they are willing and able to communicate.

In addition to the development of human capital, the model can explain differences in population size between countries and regions. Due to immigration, richer countries have, ceteris paribus, a higher population growth. However, the distribution of the immigrant population in the country of destination is not even. Immigrants are attracted to those areas where former immigrants are situated, i.e. the city. Then, without intranational migration, these clustered areas will grow faster as compared to the rest of the country or the city, thus leading to an even more uneven distribution of the immigrant population. So, in this view, network externalities will lead to agglomeration externalities.

The next subsection describes the economic setting in more detail. Thereafter, we deal with the individual's decision to migrate.

\subsection{The economy}

We start with the construction of a simple economy. Suppose that total output $Y_{j, t}$ in a country $j$ at time $t$ is defined by the following production function:

$$
Y_{j, t}=A_{j} \bar{K}_{j}^{1-\rho}\left(\sum_{i \in L_{t}} h_{i, j, t}\right)^{\rho}, \quad \rho<1,
$$

where $A_{j}$ is country-specific technology, $\bar{K}_{j}$ is the exogenously given capital stock in $j, L_{t}$ is the labor force of country $j$ at time $t$, and $h_{i, j}$ are individual-specific levels of human capital in country $j$. So, the total effective labor force in country $j$ at time $t$ equals $\Sigma_{i \in L_{t}} h_{i, j, t}$. Human capital is the only production factor for output. We assume that the accumulation of human capital is determined by the following relation (cf. Bénabou 1996b) ${ }^{7}$ :

$$
h_{i, t+1}=\Theta h_{i, t}^{\alpha} H_{k, t}^{\beta} H_{t}^{\gamma}, \quad \alpha, \beta, \gamma<1,
$$

where $\Theta$ is a constant, $H_{k, t}$ is composite human capital in neighborhood $k$ at time $t$, and $H_{t}$ is national human capital at time $t$. Furthermore, we assume that $\alpha+\beta+\gamma=1 .^{8}$ In contrast with Bénabou, we regard (2) not only as the education that a child receives, but also as the knowledge that individuals gather during their working life. Thus, individual human capital accumulation depends on three factors: namely, the individual's inherited human capital, the human capital in the local neighborhood or direct environment of the individual, and the human capital accumulated in the entire society (all displaying diminishing returns to scale).

\footnotetext{
${ }^{7}$ Country indices $j$ are omitted where it leads to no confusion.

${ }^{8}$ This ensures endogenous human capital growth, because of non-diminishing returns in the human capital accumulation function (cf. Rebelo 1991).
} 
We assume local $\left(H_{k, t}\right)$ and national $\left(H_{t}\right)$ human capital to be defined by the following CES aggregators:

$$
H_{k, t}=\left(\frac{1}{L_{k, t}} \sum_{i \in L_{k, t}} h_{i, t}^{(\varepsilon-1) / \varepsilon}\right)^{\varepsilon /(\varepsilon-1)}
$$

and

$$
H_{t}=\left(\frac{1}{L_{t}} \sum_{i \in L_{t}} h_{i, t}^{(\sigma-1) / \sigma}\right)^{\sigma /(\sigma-1)},
$$

with $L_{k, t}$ the labor force in neighborhood $k$ at time $t$. In this case, if $\varepsilon>0$ $(\sigma>0)$, then equation (3) ((4)) is convex in its argument. Heterogeneity is then a source of loss $\left(H_{k, t}<\bar{h}\left(H_{t}<\bar{h}\right)\right)$, where $\bar{h}$ denotes the average human capital, and individuals $i$ are considered to be substitutes. The larger $1 / \varepsilon(1 / \sigma)$ is, the more $H_{k, t}\left(H_{t}\right)$ will converge to the minimum of $h_{i, t}$. On the other hand, if $1 / \varepsilon<0(1 / \sigma<0)$, then $H_{k, t}\left(H_{t}\right)$ is concave, heterogeneity is a source of gains, and individuals $i$ are considered to be complements to each other. Therefore, the smaller $1 / \varepsilon(1 / \sigma)$, the more $H_{k, t}\left(H_{t}\right)$ will converge to the maximum of $h_{i, t} \cdot{ }^{9}$

Let us assume that initial human capital is lognormally distributed across individuals, with $\ln h_{i, 0} \sim N\left(\mu, \lambda^{2}\right)$. Now, we can directly link $\varepsilon$ and $\sigma$ with the human capital spillover functions, because $H_{k, t}=E\left[h_{i, t}\right] e^{-\lambda^{2} / 2 \varepsilon}$, and analogously $H_{t}=E\left[h_{i, t}\right] e^{-\lambda^{2} / 2 \sigma}$ (see Bénabou 1996b). ${ }^{10}$ This enables us to interpret $\varepsilon$ and $\sigma$ as parameters, that reflect a loss (gain) when $\varepsilon$ and $\sigma$ are positive (negative).

In order to gain insight into the behavior of the aggregator functions $H_{k, t}$ and $H_{t}$, Table 1 shows some values of $H_{k, t}\left(H_{t}\right)$ that are obtained for different values of $\varepsilon(\sigma)$ and different variances of $h_{i, t}$. Moreover, we vary the distribution of $h_{i, t}$, by using both a lognormal and a Bernoulli distribution. ${ }^{11}$

\footnotetext{
${ }^{9}$ Note that we consider individuals to be complements to each other when a heterogeneous labor force increases human capital accumulation, and they are substitutes for each other when a homogeneous labor force adds to human capital accumulation.

${ }^{10}$ Because higher moments of the lognormal distribution are defined as $E\left[h_{i, t}^{r}\right]=$ $e^{r \mu+r \lambda^{2} / 2}$ (see, e.g., Mood et al. 1974), we can write, for example, for the aggregator function $H_{t}=\left(\frac{1}{L_{t}} \sum_{i=1}^{L_{t}} h_{i, t}^{(\sigma-1) / \sigma}\right)^{\sigma /(\sigma-1)}=E\left[h_{i, t}\right] e^{-\lambda^{2} / 2 \sigma}$.

${ }^{11}$ Note that, for a Bernoulli distribution we get: $H_{t}=\left((1-p) h_{1, t}^{(\sigma-1) / \sigma}+p h_{2, t}^{(\sigma-1) / \sigma}\right)^{\sigma / \sigma-1)}$.
} 
Table 1: Simulation values of $H_{k, t}\left(H_{t}\right)$ with human capital $\left(h_{i, t}\right)$ distributed over 1000 individuals

\begin{tabular}{c|cccccc}
\hline \hline & \multicolumn{3}{|c}{ Lognormal $\left(E\left[h_{i, t}\right]=1\right)$} & \multicolumn{3}{c}{ Bernoulli $\left(E\left[h_{i, t}\right]=1\right)$} \\
\hline & \multicolumn{3}{|c}{$\operatorname{Var}\left[h_{i, t}\right]$} & & \multicolumn{3}{c}{$\operatorname{Var}\left[h_{i, t}\right]$} \\
$1 / \varepsilon, 1 / \sigma$ & 0 & 0.25 & 0.5 & 0 & 0.25 & 0.5 \\
\hline-10 & 1.000 & 2.559 & 4.021 & 1.000 & 1.408 & 1.603 \\
-2 & 1.000 & 1.286 & 1.589 & 1.000 & 1.205 & 1.358 \\
-0.5 & 1.000 & 1.072 & 1.133 & 1.000 & 1.063 & 1.126 \\
0.5 & 1.000 & 0.958 & 0.919 & 1.000 & 0.993 & 0.853 \\
2 & 1.000 & 0.815 & 0.685 & 1.000 & 0.750 & 0.499 \\
10 & 1.000 & 0.394 & 0.220 & 1.000 & 0.540 & 0.316 \\
\hline \hline
\end{tabular}

Table 1 reveals that in the presence of heterogeneity for positive $\varepsilon(\sigma)$, $H_{k, t}\left(H_{t}\right)$ will be lower than $E\left[h_{i, t}\right]$. So substitutability leads to losses from heterogeneity. In contrast, complementarity (negative $\varepsilon(\sigma)$ ) leads to gains from heterogeneity. This applies for both distribution functions, although the effects of increased heterogeneity are stronger in the case of the lognormal distribution than in the case of the Bernouilli distribution. ${ }^{12}$

Whether heterogeneity causes an increase or a decrease of the effective stock of human capital in a spatial area is an empirical question. Potentially, a larger diversification in human capital is beneficial, because of the different sets of knowledge available, indicating increasing returns to diversity. However, too large differences in human capital may prevent individuals from communicating effectively and therefore impede the transfer of knowledge, which leads to decreasing returns to diversity. ${ }^{13}$ Having specified the composites of human capital, we now have to relate human capital to individual wages, in order to fully specify the dynamics of the model.

We assume that consumers have a linear utility function, so for each individual:

$$
\max \quad U_{0}=\sum_{t=0}^{\infty} C_{t} \delta^{t}, \quad \text { s.t. } \quad C_{t} P_{C, t} \leq I_{t},
$$

where $\delta$ is the discount factor and $P_{C, t}$ the price of consumption goods. Since utility is linear, consumers have no incentive to smooth consumption. So they immediately spend all their income $\left(I_{t}\right)$ acquired by working. Thus:

$$
\sum_{i} P_{C, t} C_{i, t}=P_{Y, t} Y_{t}
$$

\footnotetext{
${ }^{12}$ In general, one can prove that, if $h_{i, t}$ is a positive random variable, then $H_{t}\left(H_{k, t}\right)$ will decrease in $1 / \sigma(1 / \varepsilon)$ (for more details, see Bénabou 1996b).

${ }^{13}$ Lazear (1999) and De Graaff (2002) empirically deal with this trade-off between different sets of knowledge and the ability to communicate. Moreover, Chiswick (1991, 1998) finds a positive relation between earnings and indigenous language proficiency among immigrants.
} 
For convenience, we normalize the output price $P_{Y, t}$ at 1 . Total profits in the economy at time $t$ are then equal to:

$$
\Pi_{t}=Y_{t}-\sum_{i \in L_{t}} w_{i, t}
$$

with $w_{i}$ the individual wage. Profits accrue to the owners of capital, who have the same utility function as consumers (equation (5)).Wages reflect the marginal product of labor (see e.g. Gravelle and Rees 1992), so:

$$
w_{i, t}=\rho A \bar{K}^{1-\rho}\left(\sum_{i \in L_{t}} h_{i, t}\right)^{\rho-1} h_{i, t} .
$$

The relative wage between two (arbitrary) individuals, $k$ and $l$, thus equals:

$$
\frac{w_{k, t}}{w_{l, t}}=\frac{h_{k, t}}{h_{l, t}},
$$

from which we can derive - using equations (1) and (8) - that

$$
\sum_{i \in L_{t}} w_{i, t}=\rho Y_{t}
$$

Basically, this defines the economy in a particular country. The next subsection presents the mechanisms driving migration between countries.

\subsection{Endogenous migration}

We suppose that there are two countries (each described by the basic economy, as laid out in the previous subsection) named the source $(s)$ and the destination $(d)$. Furthermore, the country-specific technology is strictly larger in the country of destination, due to historical or geographical factors, so $A_{d}>A_{s}$. Individuals migrate if their present discounted utility is larger in the country of destination than in the country of origin. The present discounted utility does not only depend on wages and the discount factor $\delta$, but also on migration costs. The migration costs are assumed to depend on the stock of migrants and human capital according to:

$$
c_{i, t}=c\left(P_{M, t}, h_{i, t}\right),
$$

with $P_{M, t}$ the stock of migrants in the receiving country. We assume that the migration costs decrease in the stock of migrants and individual human capital. Furthermore, $c_{i, t}>0$ always holds for each potential migrant $i$. We assume that wages in $d$ are initially higher than in $s$, due to 
better country-specific technologies $A .{ }^{14}$ Then, migrants will always flow from $s$ to $d$. Following the present value approach of Sjaastad (1962), we can now determine the maximum present discounted utility values for an individual $i$ at time $t$ in $s$, who migrates $(M)$ and in the case in which he stays $(S)$ :

$$
\begin{aligned}
V_{i, t}^{S} & =\frac{w_{i, t}^{s}}{1-\delta}, \\
V_{i, t}^{M} & =\frac{w_{i, t}^{d}}{1-\delta}-c_{i, t} .
\end{aligned}
$$

In this specification, individuals do not take future development of human capital, and thus wages, into account. So, we assume that individuals display myopic behavior instead of rational behavior. ${ }^{15}$

It is now useful to adopt from Carrington et al. (1996) the concept of the marginal migrant who has human capital $\widetilde{h}$ viz. that migrant who is indifferent between migrating and staying. Because of the monotonic decrease of costs in the stock of migrants, we can also put $\widetilde{h}=\phi\left(P_{M, t}\right)$. Using (12), the marginal migrant is indifferent between migrating or staying when the following equality holds (Carrington et al. (cf. 1996)):

$$
\frac{w_{i, t}^{d}-w_{i, t}^{s}}{1-\delta}=c\left(P_{M, t}, \phi\left(P_{M, t}\right)\right)
$$

Equation (14) basically presents a cost-benefit approach, where the costs exhibit a network externality.

Having specified the economies of the two countries and the mechanism driving international migration, we can now turn to the analysis of the relation between immigration and human capital dynamics. The next section analyzes migration and human capital accumulation in the case of within-country homogeneous human capital, so that the migration costs of (11) only depend on the stock of migrants in $d$.

\footnotetext{
${ }^{14}$ If population sizes are highly unequal, then wages in a small country with an inferior technology can be higher than in a large country with a superior technology, because there are diminishing returns to human capital. So, due to differences in factor prices, people could migrate from $d$ to $s$, even though country-specific technology might be higher in $d$. We avoid this situation by construction (i.e., the source country is assumed to be sufficiently large).

${ }^{15}$ Thus, migrants take into account the influence of the stock of migrants $(M)$ on the payoff of migrating, but not the (marginal) impact of their and future migrants' migration on future wages.
} 


\section{Within-Country Homogeneous Human Capital}

In this section, we look at the equilibrium when both country $s$ and country $d$ have a homogeneous labor force. With homogeneous human capital in the source country, every individual would migrate if migration costs are below a certain threshold. Therefore, we have to calculate an instantaneous macro-migration flow, $M_{t}$, at time $t$. Because we only analyze the effects of one migration flow in this section, we omit the time-indices for the comparative static analysis for clarity reasons.

Table 2 provides the comparative statics for the size of the instantaneous migrant flow $M$. For more details and the specification of the macroeconomic equilibrium we refer to Appendix A.

\begin{tabular}{cccccccccc}
\multicolumn{11}{c}{ Table 2: Comparative statics for $M$} \\
\hline \hline$h_{s}$ & $h_{d}$ & $A_{s}$ & $A_{d}$ & $\delta$ & $\rho$ & $P_{I}$ & $P_{s}$ & $P_{M}$ \\
+ & - & - & + & + & + & - & + & $-/+$ \\
\hline \hline
\end{tabular}

The comparative static results can be understood as follows (see Appendix A for technicalities). An increase in the human capital in the source country $\left(h_{s}\right)$ has a positive impact, because migration costs will decrease and wages in the destination $(d)$ will increase for the immigrant population relative to the source $(s)$. Human capital in the country of destination $\left(h_{d}\right)$ has a negative impact, because there are decreasing returns to total human capital. Therefore, if country $d$ has a higher amount of average human capital than country $s$, then a smaller wage will accrue to the immigrant population due to the additive character of human capital in the production function that is characterized by decreasing returns to scale. If wages in $s$ rise (due to a higher country specific technology $\left(A_{s}\right)$ ), then migration will decrease, because of a higher utility in $s$. The discount factor $(\delta)$ has a positive impact, because a higher $\delta$ means that future gains are more appreciated relative to the one-time migration costs that has to be incurred in the first period, so that more individuals will opt for the higher wages in $d$. An increase in $\rho$ increases the returns to total human capital, and therefore increases individual wages. Because initially there is assumed to be a wage gap between $s$ and $d$, wages in $d$ rise relatively stronger, which will have a positive impact on the migration flow $(M)$. If the indigenous population $\left(P_{I}\right)$ in $d$ increases, then the equilibrium value of $M$ decreases, due to decreasing returns to total human capital, and thus lower wages in $d$. Finally, a larger size of the population in $s$ will increase $M$, because of lower wages in $s$ due to higher population pressure. The effect of $P_{M}$ depends on two factors, namely, the endogenous migration costs and the effect of the size of the migrant population on the wages they earn in $d$. If $P_{M}$ is sufficiently small, then the size of the migrant community contributes positively to the migrant inflow (which can be regarded as a positive network externality 


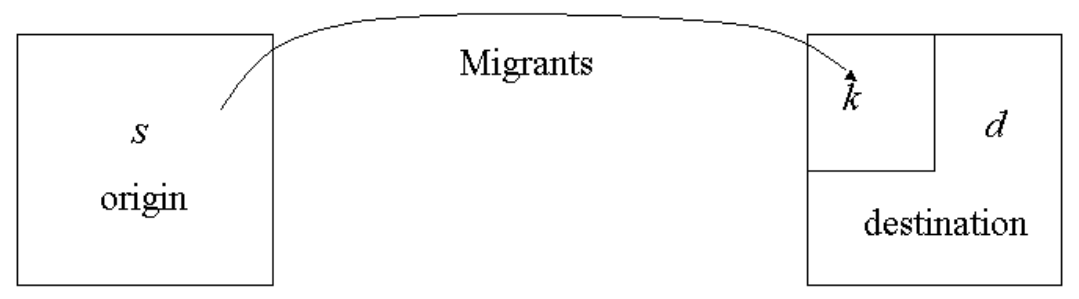

Figure 1: Geographical configuration.

for the immigrants). If, however, it is smaller, then the stock of migrants has a negative influence on $M$ (which is caused by the decreasing returns to scale in the production function).

We now turn to the dynamics of human capital accumulation. We still assume one (initial) migrant flow, in contrast to the next section where we also take the dynamics of migration into account. According to our model, migrants will only go to one neighborhood (say $k$ ) in $d .{ }^{16}$ Figure 1 shows the geographical configuration.

On the neighborhood level there is now a mixture between a (growing) group of immigrants with an amount of human capital that deviates from that of the indigenous population and a group of indigenous individuals that gets smaller. For simplicity, we assume that there is no interregional migration from $k$ to $d$. Although human capital within groups is homogeneous and we only have one migration flow, it is interesting to look at the dynamics of human capital accumulation in $s, d$ and $k$. First, using (2), it is easy to see that human capital in the source country accumulates as follows:

$$
\ln h_{s, t+1}=\theta+\ln h_{s, t},
$$

where the growth constant $\theta$ is defined as $\ln \Theta$. Immigrants in $d$ living in $k$ have the following human capital accumulation:

$\ln h_{s, k, t+1}=\theta+\alpha \ln h_{s, k, t}+$

\footnotetext{
${ }^{16}$ Regardless of where they live, immigrants earn the same wage in $d$. However, realistically, if immigrants take into account future human capital accumulation, then there is the possibility that they will pay higher migration costs to go to a less ethnically-clustered area, in order to gain a higher future wage for themselves or their children. Because we use myopic behavior of individuals, our model does not incorporate this possibility.
} 


$$
\begin{aligned}
& \frac{\beta \varepsilon}{\varepsilon-1} \ln \left(m_{k, t} h_{s, k, t}^{(\varepsilon-1) / \varepsilon}+\left(1-m_{k, t}\right) h_{d, k, t}^{(\varepsilon-1) / \varepsilon}\right)+ \\
& \frac{\gamma \sigma}{\sigma-1} \ln \left(m_{t} h_{s, k, t}^{(\sigma-1) / \sigma}+p_{k, t} h_{d, k, t}^{(\sigma-1) / \sigma}+\left(1-m_{t}-p_{k, t}\right) h_{d, t}^{(\sigma-1) / \sigma}\right) .
\end{aligned}
$$

Here, $m_{k, t}$ denotes the percentage of migrants in $k$ at time $t, m_{t}$ denotes the percentage of migrants in the whole country $d$ at time $t, p_{k, t}$ the percentage of the indigenous population in $k$ at time $t$ relative to the whole country $d, h_{s, k, t}$ is the amount of human capital of migrants in $k$ at time $t$, and $h_{d, k, t}$ is the human capital of the indigenous population in $k$ at time $t .{ }^{17}$ This specification follows from the fact that we consider the mixture between immigrants and the indigenous population, for example, in neighborhood $k$ as an Bernoulli distribution. Human capital accumulation of the indigenous population in neighborhood $k$ can be calculated analogously to the migrant population. Now, it is not difficult to see that the difference in human capital between migrants and the indigenous population in $k$ is equal to (see also footnote 11):

$$
\ln h_{s, k, t+1}-\ln h_{d, k, t+1}=\alpha\left(\ln h_{d, k, t}-\ln h_{s, k, t}\right) .
$$

So with homogeneous human capital in $s$ and $d$, differences in the levels of human capital within a neighborhood are only caused by initial differences. ${ }^{18}$ Moreover, in the long run, the difference in the levels of human capital will decrease. Eventually, all individuals in $k$ will have equal amounts of human capital. So the values of human capital will converge.

Finally, after calculating human capital accumulation in the rest of the destination country and comparing it to neighborhood $k$, we can state that $\ln h_{d, t}>\ln h_{d, k, t}$, only if:

$$
\frac{\varepsilon}{\varepsilon-1} \ln \left(m_{k, t} h_{s, k, t}^{\varepsilon-1 / \varepsilon}+\left(1-m_{k, t}\right) h_{d, k, t}^{(\varepsilon-1) / \varepsilon}\right)<\ln h_{d, t},
$$

which occurs when $\varepsilon>0$ (thus with decreasing returns to human capital diversity on a local level; see also Table 1 ), or when $m_{k}$ is sufficiently large. However, the former mechanism may cause a persistent difference between the population in $k$ and the population in the rest of the country $d$ (as long as there is diversity in human capital), where the latter mechanism causes a difference that will eventually disappear. Thus, with initial homogeneous human capital, if diverse human capital within one neighborhood hampers human capital accumulation, then neighborhoods with more diverse human capital (due to immigration) lag in their human capital accumulation compared to neighborhoods with more equal human capital. This falling behind could be caused by less communication between

\footnotetext{
${ }^{17}$ More specifically, we can define $m_{k, t} \equiv \frac{P_{M, t}}{L_{k, t}}, m_{t} \equiv \frac{P_{M, t}}{L_{t}}$ and $p_{k, t} \equiv \frac{P_{I, k, t}}{L_{t}}$, where $P_{I, k, t}$ is the indigenous population in $k$ at time $t, L_{k, t} \equiv P_{M, k, t}+P_{I, k, t}$ and $L_{t} \equiv P_{M, t}+P_{I, t}$

${ }^{18}$ Note that we assume symmetry between the learning opportunities for the indigenous and the migrant population.
} 
people with different amounts of human capital, where benefits from heterogeneous human capital can be found in different sets of knowledge between individuals. However, communication between the indigenous and the migrant population should be high to make use of these different sets of knowledge. De Graaff (2002) looks more deeply into the trade-off between communication and information sets. In the next section, we drop the assumption of within-group homogeneity and analyze the more realistic case of heterogeneous human capital.

\section{Heterogeneous Human Capital and Migration}

Because individuals differ widely in abilities, intelligence and their knowledge, homogeneity is a strong assumption. In this section, we therefore analyze human capital accumulation and migration patterns in the case where human capital is heterogeneous. Because of the analytical complexity, we resort to numerical methods. ${ }^{19}$

We assume (cf. Bénabou 1996b) that the human capital of agents is initially lognormally distributed, just as in subsection 2.1 above. Furthermore, we assume that individuals in $s$ initially have a lower mean human capital than individuals in $d$, such that $\ln h_{s, 0} \sim N\left(\mu_{s, 0}, \lambda_{s, 0}^{2}\right)<\ln h_{d, 0} \sim$ $N\left(\mu_{d, 0}, \lambda_{d, 0}^{2}\right)$. In contrast to the static migration analysis in the previous section, we now analyze the complete transition path to a migration equilibrium allowing for multiple flows of immigrants.

In this subsection, we specify the individual moving costs of (11) as:

$$
c_{i, t}\left(m_{t}, h_{i, t}\right)=\varrho m_{t}^{v} h_{i, t}^{\zeta},
$$

with $\varrho$ being a scale parameter, $\zeta<0$ and $v<0$. For the special case of $\zeta=0$ we refer to Appendix B for an analytical solution. Thus, individual migration costs decrease when human capital increases. In the more general case, the solution is no longer analytically tractable and we have to rely on numerical simulations to derive the dynamics of the full model. Table 3 displays the values of the parameters used.

We begin with a small initial stock of migrants compared to the total number of inhabitants in $d$. Furthermore, countries $s$ and $d$ have the same size. We assume that country-specific technology in $d$ is higher than in $s$. Both countries exhibit equal (exogenous) growth in human capital. Initial human capital is assumed to be slightly larger in $d$ than in $s$. Moreover, the development of human capital is mainly dependent on the size of initial human capital $(\alpha)$. The influence of the global environment $(\gamma)$ is assumed

\footnotetext{
${ }^{19}$ Appendix B analytically deals with the accumulation of human capital, both in country $s$ and in country $d$ in the case in which the cost of migration does not depend on human capital.
} 
to be more important than the influence of the local environment $(\beta)$. Finally, the higher an individual's human capital, the lower are the migration costs, due to the negative human capital coefficient $(\zeta)$.

Table 3: Simulation Framework

\begin{tabular}{r|r}
\hline \hline Initial stock of migrants: $m_{0}$ & 0.001 \\
Initial population in the source $(s)$ & 10,000 \\
Initial population in the destination $(d)$ & 10,000 \\
Initial population in the neighborhood $(k)$ & 2,500 \\
Discount factor: $\delta$ & 0.95 \\
Country-specific technology in the source $(s)$ & 1 \\
Country-specific technology in the destination $(d)$ & 2 \\
Stock of given capital $(\bar{K})$ in $s$ and $d$ & 1 \\
Growth $\Theta$ (both in $s$ and $d)$ & 1.03 \\
Initial human capital in the source $(s): \mu_{s}$ & 0 \\
Initial human capital in the destination $(d): \mu_{d}$ & 0.1 \\
Elasticity of individual human capital: $\alpha$ & 0.5 \\
Elasticity of local human capital: $\beta$ & 0.2 \\
Elasticity of national human capital: $\gamma$ & 0.3 \\
Elasticity of total human capital: $\rho$ & 0.8 \\
Human capital coefficient: $\zeta$ & -0.1 \\
Scale parameter: $\varrho$ & $5^{*} 10^{-7}$ \\
\hline
\end{tabular}

In this paper, we are mainly interested in the size of the network externality $(v)$, the local elasticity of substitution $(\varepsilon)$ and the global elasticity of substitution $(\sigma)$ on the patterns of immigration and the accumulation of human capital. First, we look at the effect of the network externality on the size and pattern of immigration. Figure 2 maps out the relation between the absolute stock of migrants in $d$ and the size of the network externality $(v)$, using the configuration depicted in Table 3.

Figure 2 shows that a stonger network externality ( $v$ lower) causes a higher level of equilibrium in- and outmigration. This is caused by the low moving costs. Due to the specific functional form chosen in (19), small stocks of migrants incur high moving costs when large network externalities are present. As a consequence, the size of migration is relatively small in early time periods compared to the size of migration when no network externalities are present.

The next question that arises is to what extent do the local $(\varepsilon)$ and global $(\sigma)$ elasticities of substitution have an impact on the human capital accumulation of individuals living in $k, s$, and $d$ ? The answer to this question depends on the hypothesis chosen regarding these elasticities. We investigate here two possible cases. 


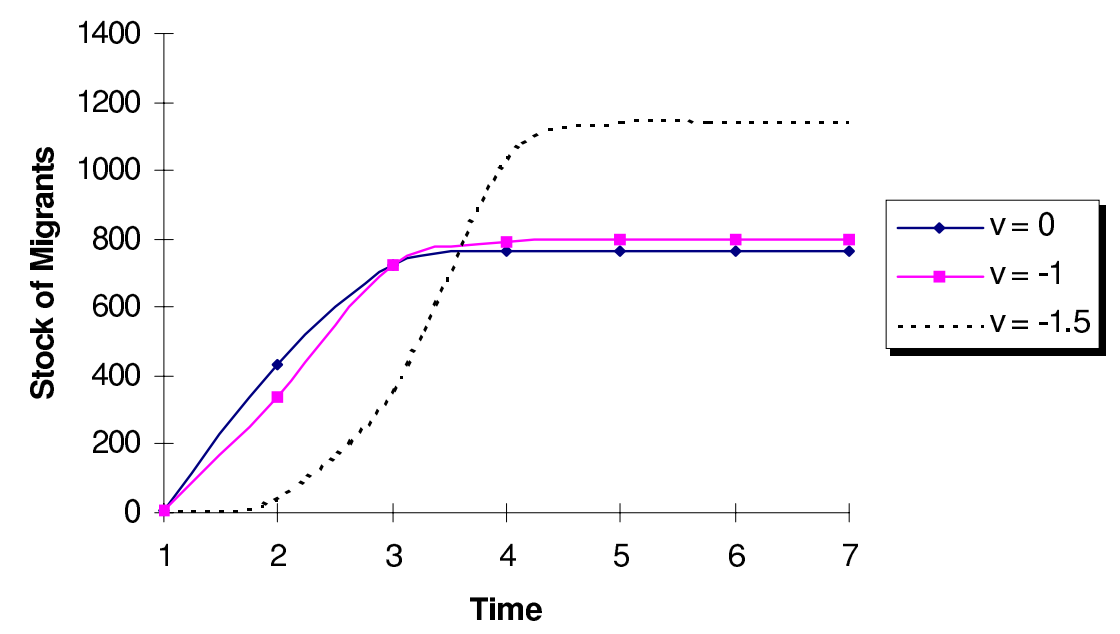

Figure 2: Migration patterns with different network externality sizes (with $\varepsilon=0.5$ and $\sigma=-1)$.

\subsection{Negative impact of the neighborhood}

First, we assume that on a neighborhood level heterogeneity has a strong negative impact on the development of human capital, where it has a weakly positive impact on the development of human capital on a national level. So, $\varepsilon$ must be slightly larger than 0 and $\sigma$ must be negative and, in an absolute sense, larger than $\varepsilon$. We can interpret this case as a situation in which the migrant population and the indigenous population in $k$ have difficulties in communicating, due to large cultural and language differences. They will not learn from each other, which hampers human capital accumulation. On the other hand, on a national level, the new influx of immigrants can be beneficial, because the enlarged population demands and supplies a larger variety of products, there are more niche markets, and there is a broadening of culture in general. Figure 3 shows the human capital accumulation for this particular case, when the neighborhood $k$ is highly segregated.

In Figure $3, k_{-} d$ and $k_{-} s$ denote, respectively, the indigenous and immigrant population in $k$. One can observe that, although the immigrants have the highest amount of human capital, it deteriorates quickly. The same holds for the indigenous population in $k$. Because heterogeneity slows down human capital accumulation, the human capital of individuals living in $k$ deteriorates for a long time, until, in the end, it converges to that of 


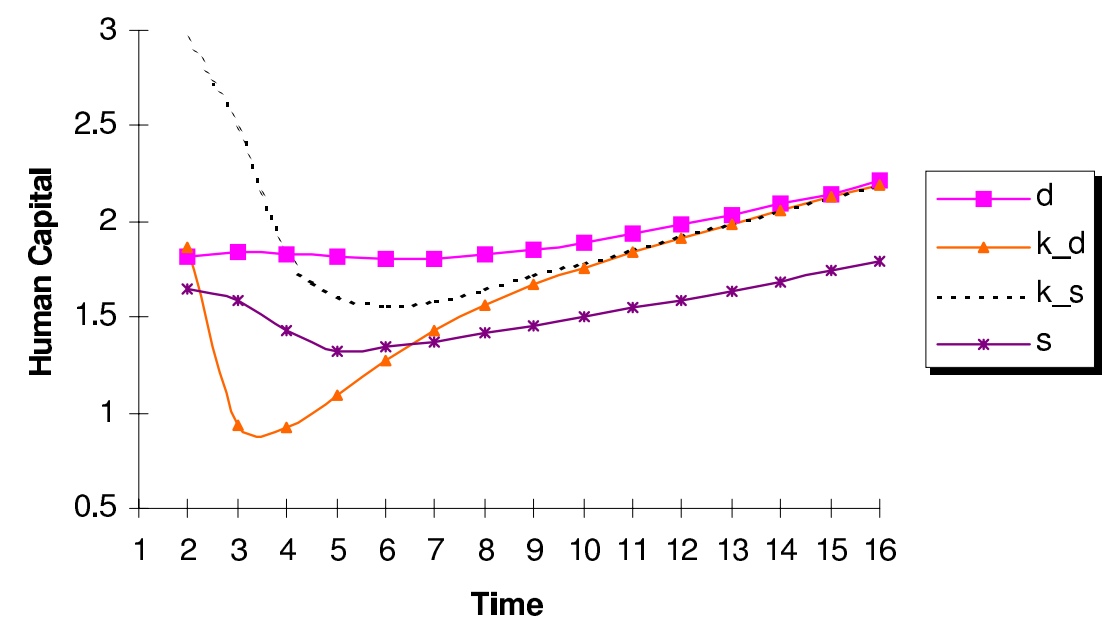

Figure 3: Human capital accumulation (with $\varepsilon=0.1, \sigma=-2$ and $v=$ $-1.5)$.

the rest of the country $(d)$.

\subsection{Positive impact of the neighborhood}

In our second case, we assume that on a neighborhood level heterogeneity has a strongly positive impact on the development of human capital, whereas it has a weakly negative impact on the development of human capital on a national level. Then $\varepsilon$ must be slightly smaller than 0 and $\sigma$ must be positive and - in an absolute value - be larger than $\varepsilon$. We may interpret this case as a situation where there are large learning effects when immigrants and the indigenous population live close together. Consider, for example, the case where the immigrant and native languages are rather similar. Then individuals have few barriers in communicating. These spillovers could then be beneficial for neighborhood $k$, but negative for the rest of the country $d$. The latter effect can be caused by a brain drain of immigrants with high human capital from the rest of the country to neighborhood $k$, because of the high human capital spillovers. Figure 4 shows the human capital accumulation for this configuration of parameters.

Figure 4 reveals that in the long run the human capital of immigrants again decreases. But because the human capital of the indigenous popula- 


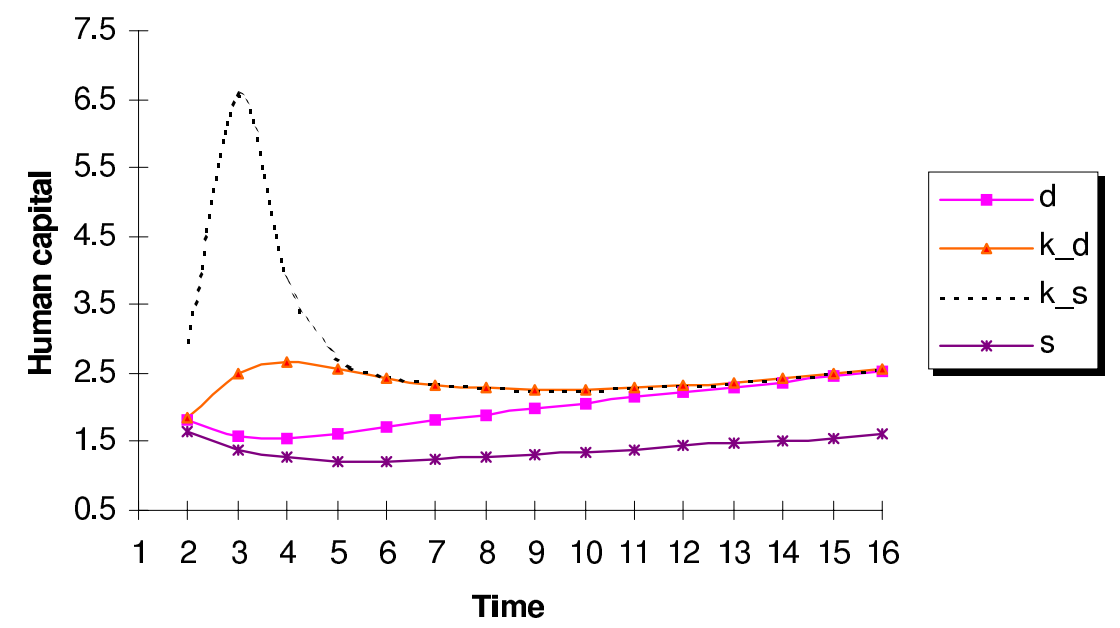

Figure 4: Human capital accumulation (with $\varepsilon=-0.1, \sigma=2$ and $v=$ $-1.5)$.

tion increases, average human capital in $k$ remains above that of the rest of $d$ and will only slowly converge to the level of $d$. Average human capital in $s$ will - in the long run - grow at the same rate as human capital in $d$, but its level will remain lower, so that there is no absolute convergence, but only relative convergence. The main differences between Figure 3 and Figure 4 apply to the short run. Due to the composition effect, individuals living in $k$ witness their human capital decrease in Figure 3 in the short run, while the human capital in $k$ in Figure 4 receives a large boost in the short run. Furthermore, just as in Figure 3, initially the highly-skilled immigrants leave, causing a brain drain from $s$ in the short run, from which average human capital in $s$ only slowly recovers. ${ }^{20}$

Historical and contemporary evidence shows that both cases can occur. The processes shown in Figure 3 can be seen in most Western European countries and in the integration of former guest workers. Because these immigrants came from further away than before, communication between the immigrant and indigenous population was, and still is, difficult, and does not occur as often as within groups. Therefore, immigrants and the

\footnotetext{
${ }^{20}$ Although the international literature often assumes that high-skilled immigrants have lower moving costs than low-skilled immigrants, there is actually not much empirical evidence for this assumption. Stalker (1994) suggests that it is not necessarily the most highly skilled on a national level who are the first to leave their source country, but the most highly skilled on a city or village level.
} 
indigenous population act as substitutes on a local level in their human capital accumulation. On the other hand, migrants who act as complements for the indigenous population (cf. Figure 4) are nowadays typically high-skilled immigrants. Obviously, scientists are among them, but also exchange students, expatriates, ICT-workers, and the like. Communication between these immigrants and the indigenous population is mostly in English and does not raise many problems. These immigrants - although they form a relatively small minority compared to the lower skilled migrants usually live in upmarket neighborhoods. In addition to these two cases, other kinds of human capital accumulation processes can occur, depending on the values of $v, \sigma$ and $\varepsilon$, and the relative levels of human capital. However, in most Western European countries a process with local substitution seems to be the most prevalent.

\section{Conclusion}

This paper developed a model to analyze the relation between endogenous migration and human capital accumulation affected by knowledge spillovers among individuals. In the basic version of the model, we considered the simple case of homogeneous human capital within a country. Here, we concluded that the relation between the stock of migrants and the extent of immigration is ambiguous. If the stock of migrants is large, then network externalities ensure lower migration costs and thus a higher number of immigrants. However, if the stock of migrants becomes too large, wages will decrease because of decreasing returns to scale in aggregate human capital. ${ }^{21}$

For the more extended version of the model in which we allowed for heterogeneous human capital within a population, we had to resort to numerical methods. The results indicate that, within a country, the human capital of the migrants and that of the indigenous population will eventually converge, although only after a considerable time period. As expected, the results indicate the presence of a brain drain from the source country, because the more highly skilled are assumed to be the first to leave. ${ }^{22}$ However, the average human capital of the high-skilled migrants will quickly decrease to that of the indigenous population in the same spatial area. Whether average human capital in this clustered area will be

\footnotetext{
${ }^{21}$ Evidently, in the presence of downward wage-rigidity, these decreasing returns to scale assumptions will show up in relatively high unemployment rates as is consistent with stylized empirical facts.

${ }^{22}$ Recently, some authors (Stark et al. 1997, Beine et al. 2001) argued that brain drains could be potentially beneficial for source countries. The reason is that because of higher returns in potential destination countries more investments will be made by the population in the source country in human capital, so that in the long run growth and brain drains could be positively correlated.
} 
lower or higher than in the rest of the country, depends on the level of communication between the immigrant and indigenous population. If their individual human capital is complementary in human capital accumulation, so that individuals will learn from each other faster in the case of heterogeneous levels of human capital, then average human capital in the clustered area will be higher than in the rest of the country. On the other hand, if their human capital can be considered as substitutes, then average human capital in the clustered area remains lower than in the rest of the country for a long time. Because of the direct relationship between wages and human capital, this will have direct consequences for the distribution of earnings within a country.

We also considered the effect of stronger network externalities on the process of migration. First, these network externalities enhance migration. Second, they ensure that the size of the stock of migrants follows a sigmoid pattern over time. Initially, migration will start slowly, then it accelerates because of the network effect on the migration costs. Thereafter, migration will decelerate because of the diminishing returns to human capital, until, finally, net migration is zero. All migration theories that take network externalities into account will have similar effects as in this paper as long as low-skilled migrants will have incentives to cluster with high-skilled migrants. They can thus provide insight into the cause of spatial heterogeneity and its evolution over time. Moreover, they generate insights into the causes of lagging performance of particular ethnic groups in terms of skill acquisition.

\section{A Comparative Statics}

Combining equilibrium equation (3.11) with wage equation (3.8) gives us the following relation:

$$
\begin{aligned}
\frac{(1-\delta)}{\rho} c\left(P_{M}, h_{s}\right)= & \frac{\left(P_{I} h_{d}+\left(P_{M}+M\right) h_{s}\right)^{\rho-1}}{P_{I} \frac{h_{d}}{h_{s}}+\left(P_{M}+M\right)} A_{d}- \\
& \frac{\left(\left(P_{s}-M\right) h_{s}\right)^{\rho-1}}{P_{s}-M} A_{s} .
\end{aligned}
$$

The cost of migration is equal for every migrant because of homogeneous human capital in $s$. Note, that in this specification everyone within one country with the same human capital receives the same wage, so, for example, migrants in $d$ receive $\frac{h_{s}}{P_{I} h_{d}+\left(P_{M}+M\right) h_{s}} P_{Y} Y_{d}$. Moreover, because migrants leave $s$, population will decrease in $s$ and marginal returns to human capital, and thus the wage, will increase in $s$.

To derive the comparative statics characteristics of the model, we can use the implicit function theorem (see, e.g., Chiang 1984). First, we define the implicit function $\Phi$ as follows: 


$$
\begin{aligned}
\Phi= & \frac{1-\delta}{\rho} c\left(P_{M}, h_{s}\right)-h_{s} A_{d}\left(P_{I} h_{d}+\left(P_{M}+M\right) h_{s}\right)^{\rho-2}+ \\
& A_{s}\left(P_{s}-M\right)^{\rho-2} h_{s}^{\rho} .
\end{aligned}
$$

Then, using the implicit function theorem, we get $\frac{d M}{d x}=-\frac{\Phi_{1}^{\prime}(x, M)}{\Phi_{2}^{\prime}(x, M)}$, if $\Phi_{2}^{\prime}(x, M)$ $\neq 0$ where $x$ is a parameter of the model. The determination of the signs of the derivatives as presented in Table 2 is now straightforward, except for two. First, the sign of the partial derivative of $\Phi$ with respect to $\rho$ is not immediately clear, but we can write:

$$
\begin{aligned}
\frac{\partial \Phi}{\partial \rho}= & -\frac{1}{\rho^{2}} \times \\
& \left\{(1-\delta) c\left(P_{M}, h_{s}\right)+\right. \\
& h_{s}\left(P_{I} h_{d}+h_{s}\left(P_{M}+M\right)\right)^{\rho-2}\left(\ln \left(P_{I} h_{d}+h_{s}\left(P_{M}+M\right)\right)\right) A_{d} \rho^{2} \\
& \left.-h_{s}\left(\left(P_{s}-M\right) h_{s}\right)^{\rho-2}\left(\ln \left(P_{s}-M\right) h_{s}\right) A_{s} \rho^{2}\right\} \\
< & 0
\end{aligned}
$$

where the sign of $\frac{\partial \Phi}{\partial \rho}$ is negative, provided that:

$$
P_{I} \frac{h_{d}}{h_{s}}+P_{M}+2 M+(1-\delta) c\left(P_{M}, h_{s}\right)>P_{s}
$$

(given that $A_{s} \leq A_{d}$ ).

Second, the partial derivative of $\Phi$ with respect to the stock of migrants is not immediately clear and equals:

$$
\begin{aligned}
\frac{\partial \Phi}{\partial P_{M}}= & \frac{(1-\delta)}{\rho} \frac{\partial c\left(P_{M}, h_{s}\right)}{\partial P_{M}}+ \\
& \frac{(2-\rho) h_{s}}{\rho} \frac{\rho\left(P_{I} h_{d}+h_{s}\left(P_{M}+M\right)\right)^{\rho-1} h_{s} A_{d}}{\left(P_{I} h_{d}+h_{s}\left(P_{M}+M\right)\right)^{2}} \\
= & \underbrace{\frac{(1-\delta)}{\rho} \frac{\partial c\left(P_{M}, h_{s}\right)}{\partial P_{M}}}_{<0}+\underbrace{\frac{(2-\rho) h_{s}}{\rho\left(P_{I} h_{d}+h_{s}\left(P_{M}+M\right)\right)} w_{h_{s}}^{d}}_{>0}
\end{aligned}
$$

with $w_{h_{s}}^{d}$ the wage that someone with low human capital $\left(h_{s}\right)$ will earn in $d$. It is now easy to see that eventually (for $P_{M}$ sufficiently large) the second term will dominate the first term. 


\section{B Human capital accumulation when migration costs do not depend on human capital}

We first assume that human capital in country $s$ is equally distributed for each individual. Then growth in expected human capital in country $s$ is straightforwardly denoted as (see also footnote 10):

$$
\mu_{s, t+1}=\theta+\mu_{s, t}+\gamma \frac{\sigma-1}{\sigma} \frac{\lambda_{s, t}^{2}}{2},
$$

with variance: $\lambda_{s, t+1}^{2}=(\alpha+\beta)^{2} \lambda_{s, t}^{2}$, which converges to 0 . The human capital distribution in $s$ remains lognormally distributed. However, this is not the case for the human capital distribution in $d$. In the country of destination, every group of migrants and indigenous population is lognormally ditributed, and where total population in $k$ or the rest of $d$ is the sum of lognormal distributions. Therefore, analytical expressions for the growth in expected human capital in areas in $d$ are - although feasibile - not insightful. Instead, we may look at the differences in expected human capital accumulation. The difference in expected human capital growth between the indigenous and the migrant population in $k$ can again be denoted as:

$$
\mu_{d, k, t+1}-\mu_{s, k, t+1}=\alpha\left(\mu_{d, k, t}-\mu_{s, k, t}\right) .
$$

Because $\alpha<1$, human capital within a neighborhood will converge by construct. If we, e.g., want to model the ethnic capital concept of Borjas $(1992,1995)$, then we have to allow for different human capital spillovers for the migrant and the indigenous population. Here, we are especially interested in the difference in human capital accumulation between the migration population inside and the indigenous population outside neighborhood $k$. Unfortunately, the expression is rather complex and equals:

$$
\mu_{d, t+1}-\mu_{s, k, t+1}=\alpha\left(\mu_{d, t}-\mu_{s, k, t}\right)+\beta\left(\mu_{d, t}-E \ln \left[H_{k, t}\right]\right),
$$

with:

$$
\begin{aligned}
E \ln \left[H_{k, t}\right]= & \frac{\varepsilon}{\varepsilon-1} \ln \\
& \left\{\sum_{\tau=0}^{t-1} m_{k, t, t-\tau}\left(E\left[h_{d, s, t, t-\tau}\right] \exp \left\{-\frac{\lambda_{d, s, t, t-\tau}^{2}}{2 \varepsilon}\right\}\right)^{\frac{\varepsilon-1}{\varepsilon}}\right. \\
& \left.+\left(1-\sum_{\tau=0}^{t-1} m_{k, t, t-\tau}\right)\left(E\left[h_{d, k, t}\right] \exp \left\{-\frac{\lambda_{d, k, t}^{2}}{2 \varepsilon}\right\}\right)^{\frac{\varepsilon-1}{\varepsilon}}\right\}
\end{aligned}
$$

where $\sum_{\tau=0}^{t-1} m_{k, t, t-\tau}$ denotes all migrant groups, who came to $k$ in the past. All migrant and indigenous groups in (28) seperate are still lognor- 
mally distributed. However, the expectation of $H_{k, t}$ is affected by some weighted average of expectations of the human capital of the various groups living in $k$. Basically, equation (28) has the same characteristics as those described in footnote 9 . So again, whether human capital in $k$ is larger than in $d$ depends on the size of the group of migrants and the value of $\varepsilon$. If $\varepsilon$ is larger than zero, then there are again decreasing returns to diversity. Otherwise there are increasing returns to diversity. Thus, with heterogenous human capital the analytical results do not change in nature. Due to the larger variation in human capital, it is likely that the dynamic evolution of human capital accumulation fluctuates more strongly whenincorporating heterogenous human capital. In this setting, the parameter $\sigma$ being a national parameter does not have any influence on differences in human growth within a country. If there are national returns to diversity $(\sigma<0)$, then immigration will benefit a country as a whole, because of the inflow of different amounts of human capital.

Note that the variances in human capital will eventually converge to zero for all groups, due to the fact that we do not allow for idiosyncratic shocks in human capital accumulation. Therefore, human capital differences within a country will eventually disappear, because of the averaging influence of human capital in the neighborhood and the country as a whole. However, we know that idiosyncratic shocks do occur. For example, persons are born. Therefore, convergence does not necessarily occur in practice.

\section{References}

Bartel, A. P.: 1989, Where do the new u.s. immigrants live?, Journal of Labor Economics 7, 371-391.

Becker, G. S.: 1975, Human Capital: A Theoretical and Empirical Analysis with Special Reference to Education, Columbia University Press, New York.

Beine, M., Docquier, F. and Rapoport, H.: 2001, Brain drain and economic growth: Theory and evidence, Journal of Development Economics 64, 275289.

Bénabou, R.: 1996a, Equity and efficiency in human capital investment: The local connection, Review of Economic Studies 63, 237-264.

Bénabou, R.: 1996b, Heterogeneity, stratification, and growth: Macroeconomic implications of community structure and school finance, American Economic Review 86, 584-609.

Bertrand, M., Luttmer, E. F. P. and Mullainathan, S.: 2000, Network effects and welfare cultures, Quarterly Journal of Economics 115, 1019-1055. 
Borjas, G. J.: 1992, Ethnic capital and intergenerational mobility, Quarterly Journal of Economics 107, 123-150.

Borjas, G. J.: 1994, The economics of immigration, Journal of Economic Literature 32, 1667-1717.

Borjas, G. J.: 1995, Ethnicity, neighborhoods, and human-capital externalities, American Economic Review 85, 365-390.

Carrington, W. J., Detragiache, E. and Vishnawath, T.: 1996, Migration with endogenous moving costs, American Economic Review 86, 911-930.

Chiang, A. C.: 1984, Fundamental Methods of Mathematical Economics, McGraw-Hill, Singapore.

Chiswick, B. R.: 1991, Speaking, reading, and earnings among low-skilled immigrants, Journal of Labor Economics 9, 149-170.

Chiswick, B. R.: 1998, Hebrew language usage: Determinants and effects on earnings among immigrants in israel, Journal of Population Economics 11, 253-271.

Cutler, D. M. and Glaeser, E. L.: 1997, Are ghettos good or bad?, Quarterly Journal of Economics 112, 827-872.

De Graaff, T.: 2002, Migration, Ethnic Minorities and Network Externalities, Thela Thesis, Amsterdam.

De Vries, J. and Van der Wouden, A.: 1995, The First Modern Economy : Success, Failure, and Perseverance of the Dutch Economy, 1500-1815, Balans, Amsterdam.

Durlauf, S. N.: 1994, Spillovers, stratification, and inequality, European Economic Review 38, 836-845.

Dustmann, C. and Preston, I.: 2001, Attitudes to ethnic minorities, ethnic context and location decisions, Economic Journal 111, 353-373.

Edin, P.-A., Fredriksson, P. and Åslund, O.: 2003, Ethnic enclaves and the economic success of immigrants - evidence from a natural experiment, Quarterly Journal of Economics 118, 329-357.

Epstein, G. S. and Hillman, A.: 1998, Herd effects and migration. CEPR, London.

Gravelle, H. and Rees, R.: 1992, Microeconomics, Longman Publishing, New York.

Greenwood, M. J. and McDowell, J. M.: 1986, The factor market consequences of u.s. immigration, Journal of Economic Literature 24, 1738-1772. 
Hendricks, L.: 2001, The economic performance of immigrants: A theory of assortive matching, International Economic Review 42, 417-449.

Islam, N.: 1995, Growth empirics: A panel data approach, Quarterly Journal of Economics 110, 1127-1170.

LaLonde, R. and Topel, R. H.: 1991, Immigrants in the american labor market: Quality, assimilation, and distributional effects, AEA Papers and Proceedings 81, 297-302.

Lazear, E. P.: 1999, Culture and language, Journal of Political Economy 106, S95-S126.

Lucas, E. P.: 1988, On the mechanics of economic development, Journal of Monetary Economics 22, 3-42.

Manski, C. F.: 1993, Identification of endogenous social effects: The reflection problem, Review of Economic Studies 60, 531-542.

Massey, D. S., Arango, J., Hugo, G., Kouaouci, A., Pellegrino, A. and Taylor, J. E.: 1993, Theories of international migration: A review and appraisal, Population and Development Review 19, 431-466.

Mokyr, J.: 1999, The British Industrial Revolution: An Economic Perspective, Westview Press, Boulder.

Montgomery, J.: 1991, Social networks and labor market analysis, American Economic Review 91, 1407-1418.

Mood, A. M., Graybill, F. A. and Boes, D. C.: 1974, Introduction to the Theory of Statistics, McGraw-Hill, Singapore.

Munshi, K.: 2003, Networks in the modern economy:mexican migrants in the u.s. labor market, Quarterly Journal of Economics 118, 549-599.

Rebelo, S.: 1991, Long-run policy analysis and long-run growth, Journal of Political Economy 99, 500-521.

Romer, P. M.: 1986, Increasing returns and long-run growth, Journal of Political Economy 94, 1002-1037.

Sjaastad, L. A.: 1962, The costs and returns of human migration, Journal of Political Economy 70, 80-93.

Stalker, P.: 1994, The Work of Strangers: A Survey of International Labour Migration, International Labour Office, Geneva.

Stark, O.: 1991, The Migration of Labor, Basil Blackwell, Cambridge. 
Stark, O.: 1994, Patterns of Labor Migration when Workers Differ in their Skills, Springer-Verlag, Economic Aspects of International Immigration, pp. 5774.

Stark, O., Prskawetz, A. and Helmenstein, C.: 1997, A brain gain with a brain drain, Economics Letters 55, 227-234. 